\title{
Welding Residual Stress Distribution of Quenched and Tempered and Thermo-Mechanically Hot Rolled High Strength Steels
}

\author{
Thomas Schaupp ${ }^{1, a^{*}}$, Dirk Schroepfer ${ }^{1, b}$, Arne Kromm, c \\ and Thomas Kannengiesser ${ }^{1, d}$

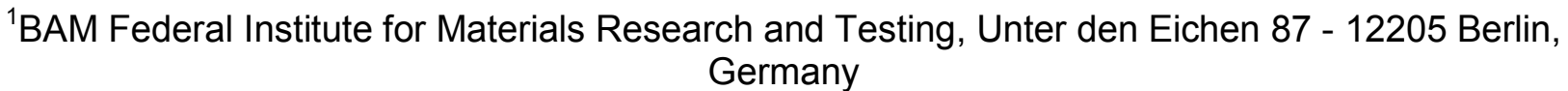

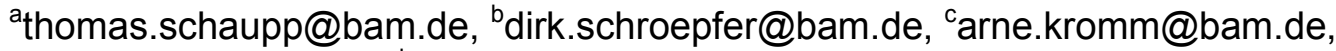 \\ thomas.kannengiesser@bam.de
}

\begin{abstract}
Keywords: Quenched and Tempered High Strength Steel, Thermo-Mechanical Controlled Process, Welding, Mill Scale, Residual Stress.
\end{abstract}

\begin{abstract}
Beside quenched and tempered (QT) high strength steels advanced technologies in steel manufacturing provide steels produced by the thermo-mechanical controlled process (TMCP) with yield strength of $960 \mathrm{MPa}$. These steels differ in the carbon and micro-alloying element content. With variation of heat control TIG-welded dummy seams on both steel types were performed. Analyses concerning microstructure and residual stress evolution due to welding showed typical stress distributions according to common concepts. Yet, the TMCP-steel shows higher residual stresses than the QT-steel.
\end{abstract}

\section{Introduction}

High strength steels with yield strengths $\geq 690 \mathrm{MPa}$ are applied in modern steel structures by a considerably increasing number of industry sectors, as a result of current trends towards lightweight structures. By reducing the wall thickness, remarkable weight savings and lower processing costs are achievable [1]. While quenched and tempered (QT) high strength steels were found for most applications in the past, steels produced by the thermo-mechanical controlled process (TMCP) are becoming increasingly important [2,3]. Mainly these steels differ in the manufacturing process and in the chemical composition. High strength QT-steels contain a carbon content of less than $0.2 \%$ and are water quenched to obtain a transformation into martensite or bainite followed by a tempering process [1]. In comparison TMCP-steels comprise less carbon but a higher content of microalloying elements, which lead to a precipitation hardening effect [3].

Usually the TMCP-steels are provided with a mill scale. This oxide scale is formed at high temperatures during the manufacturing process and consists of wustite $(\mathrm{FeO})$, intermediate magnetite $\left(\mathrm{Fe}_{3} \mathrm{O}_{4}\right)$ and hematite $\left(\mathrm{Fe}_{2} \mathrm{O}_{3}\right)$ [4]. The elements vary depending on plate thickness, chemical composition and the cooling conditions. The oxygen in the scale is a surface active element [5-7]. When a surface active element is present in a molten pool, the surface tension gradient can change from negative to positive. As a result the cooler liquid metal of lower surface tension at the edge of the pool is pulled inward by the warmer liquid metal of higher surface tension. This fluid flow transfers heat to the weld root and a narrow and deep weld is formed $[8,9]$. In the absence of surface active elements, the surface tension of molten metal decreases with increasing temperature. A broad and shallow weld results $[8,9]$.

The deeper molten zone may lead to an inhomogeneous cooling of the weld seam because of a larger heat affected area. Therefore, higher temperature of the core of a weld results in a delayed phase transformation compared to the surface zone. Thus, high tensile residual stresses can be generated on the surface zones of the weld seam [10]. In the prevailing standards EN 1011-1 [11] and EN 1090-2 [12] the removal of rust, oxides and scale at the welding area is prescribed, but an explicit reason is not given. Hence, in this present study correlation between the fluid flow induced by a mill scale and the transverse residual stresses in high strength steel welds are discussed. 


\section{Experimental}

Materials. For the analyses a QT-steel S960QL and a TMCP-steel S960MC showing a mill scale were used. The chemical compositions are provided in Table 1. The mechanical properties are shown in Table 2. The strength as well as the hardness of both steels are similar. Both test material plates have a thickness of $8 \mathrm{~mm}$. The microstructures are shown in Fig. 1. Both structures contain bainite and tempered martensite. In the QT-steel S960QL fine dispersed carbides can be detected. Hard precipitates are present in the TMCP-steel S960MC.

Table 1: Chemical compositions (wt \%) of the test materials

\begin{tabular}{|c|c|c|c|c|c|c|c|c|c|c|c|c|}
\hline & $\mathrm{C}$ & $\mathrm{Si}$ & $\mathrm{Mn}$ & $\mathrm{N}$ & $\mathrm{B}$ & $\mathrm{Cr}$ & $\mathrm{Cu}$ & $\mathrm{Mo}$ & $\mathrm{Nb}$ & $\mathrm{V}$ & $\mathrm{Ni}$ & $\mathrm{Ti}$ \\
\hline S960QL $^{\text {a) }}$ & 0.12 & 0.23 & 1.27 & 0.008 & 0.0007 & 0.2 & 0.01 & 0.59 & 0.015 & 0.05 & 0.059 & 0.01 \\
\hline S960MC $^{\text {b) }}$ & 0.095 & 0.13 & 1.68 & 0.01 & 0.001 & 0.9 & 0.03 & 0.2 & 0.005 & 0.1 & 0.46 & 0.02 \\
\hline${ }^{\text {a) }} \mathrm{EN}^{10025-6,{ }^{\text {b) }}} \mathrm{EN} 10149-2,{ }^{\text {c) }} \mathrm{EN} 1011-2$ \\
\hline
\end{tabular}

Table 2: Mechanical properties of the test materials

\begin{tabular}{|c|c|c|c|c|}
\hline & $\begin{array}{c}\text { Yield Strength } R_{\mathrm{p} 0.2} \\
{[\mathrm{MPa}]}\end{array}$ & $\begin{array}{c}\text { Ultimate Tensile Strength } \\
R_{\mathrm{m}}[\mathrm{MPa}]\end{array}$ & $\begin{array}{c}\text { Total Elongation } A \\
{[\%]}\end{array}$ & $\begin{array}{c}\text { hardness } \\
{[\mathrm{HV} 10]}\end{array}$ \\
\hline S960QL & $960^{\mathrm{a})}$ & 980 to $1150^{\mathrm{a})}$ & $\min .10^{\mathrm{a})}$ & $354 \pm 3^{\mathrm{c})}$ \\
\hline S960MC & $960^{\mathrm{b})}$ & 980 to $1250^{\mathrm{b})}$ & $\min .7^{\mathrm{b})}$ & $335 \pm 3^{\mathrm{c})}$ \\
\hline${ }^{\mathrm{a})}$ EN 10025-6, ${ }^{\mathrm{b})}$ EN $10149-2,{ }^{\text {c) }}$ hardness testing according to EN ISO 6507-1 \\
\hline
\end{tabular}
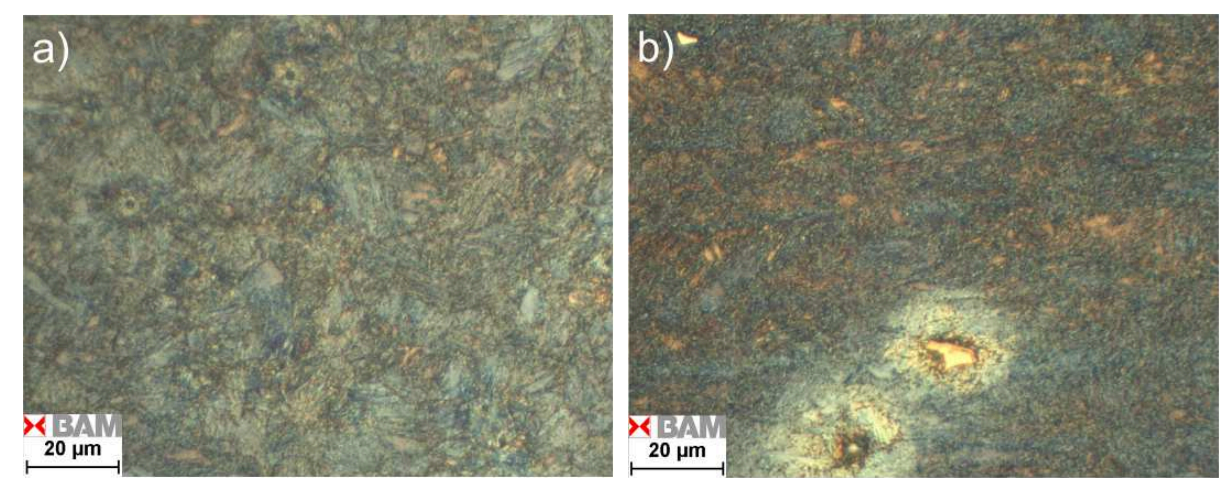

Fig. 1: Microstructure of the test materials after Beraha I etching: a) QT steel S960QL, b) TMCP steel S960MC

Welding. Free shrinking weld tests were made by using the TIG-welding process. On the plates dummy seams were produced with a tungsten electrode $(\varnothing 4 \mathrm{~mm})$ under argon atmosphere. The benefit of dummy seams is, that the formation of residual stresses can be analysed excluding the disturbing effect of mixing of filler and base materials. The dimensions of the plates were $110 \mathrm{~mm} \times 80 \mathrm{~mm} \times 8 \mathrm{~mm}$ (length $\times$ width $\times$ thickness). The weld seams were applied centrically on the plates with a length of $80 \mathrm{~mm}$. To accomplish a stable welding process, welding voltage and current were adjusted constant. Consequently the variation of heat input $E$ was realised by a modification of the welding speed $v$. Table 3 represents the welding parameters for the TIG-welded dummy seams and the experimentally determined $\Delta t_{8 / 5}$-cooling times.

For the determination of the $\Delta t_{8 / 5}$-cooling times type-K thermo couples with a diameter of $0.5 \mathrm{~mm}$ as well as a two colour pyrometer were used. The temperature was measured in the weld centre at the weld seam length of $55 \mathrm{~mm}$. The local residual stresses in the weld seam area were measured via $X$-ray diffraction using the $\sin ^{2} \psi$-method on the top surface. Table 4 contains some experimental details for the residual stress analysis. 
Table 3: Welding parameters for the TIG-welded dummy seams on the steels S960QL and S960MC

\begin{tabular}{|c|c|c|}
\hline Test nr. & 1 & 2 \\
\hline Heat input $E[\mathrm{~kJ} / \mathrm{mm}]$ & 0.5 & 0.9 \\
\hline Welding voltage $U[\mathrm{~V}]$ & 12 & 12 \\
\hline Welding current $I[\mathrm{~A}]$ & 275 & 275 \\
\hline Welding speed $v[\mathrm{~mm} / \mathrm{min}]$ & 400 & 220 \\
\hline$\Delta t_{8 / 5}$-cooling time for S960QL $[\mathrm{s}]$ & 2.5 & 9.4 \\
\hline$\Delta t_{8 / 5}$-cooling time for S960MC $[\mathrm{s}]$ & 3.0 & 7.9 \\
\hline
\end{tabular}

Table 4: Experimental details for the X-ray diffraction using the $\sin ^{2} \psi$-method

\begin{tabular}{|c|c|}
\hline Radiation & $\mathrm{CrK}_{\alpha}$ \\
\hline Power & Current $I=6.7 \mathrm{~mA}$, voltage $U=30 \mathrm{kV}$ \\
\hline Collimator & $\varnothing 2 \mathrm{~mm}$ \\
\hline Lattice plane & Ferrite: $211\left(2 \Theta_{0}=156^{\circ}\right)$ \\
\hline$\psi$-range & $-45^{\circ}$ to $45^{\circ}(6$ steps $)$ \\
\hline
\end{tabular}

\section{Results and discussion}

Fluid flow in the weld pool. Fig. 2 presents the macrosections of the dummy seams of the QT-steel S960QL. Both pictures show a relatively wide and shallow weld. This can be explained with the models of Heiple et al. [8,9]. In the absence of oxygen (mill scale), the surface tension of molten metal decreases with increasing temperature. Therefore the surface tension will be greatest at the edge of the weld pool and the highest under the arc. The surface tension gradient produces fluid flow from the centre of the molten pool to the edge.
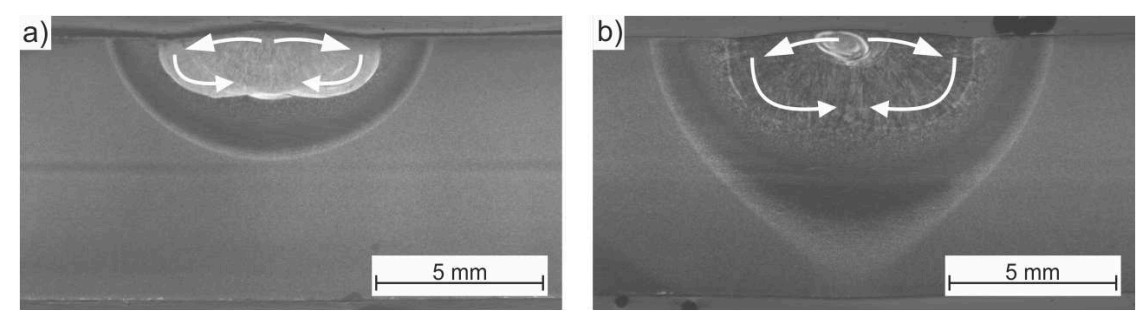

Fig. 2: Macrosections of the TIG-welded dummy seams of the QT-steel S960QL: a) test nr. 1, $\Delta t_{8 / 5}=2.5 \mathrm{~s}, \mathrm{~b}$ ) test nr. $2, \Delta t_{8 / 5}=9.4 \mathrm{~s}$; fluid flow indicated by arrows

For the dummy seams of the TMCP-steel S960MC with a mill scale, a different characteristic can be noticed, cp. Fig. 3. A narrower and deeper welded zone is formed compared to respective welds without mill scale influence. The oxygen in the scale changes the temperature dependence of the surface tension, so that the surface tension of the molten pool increases with increasing temperature $[8,9]$. The surface tension gradient produces fluid flow from the edge of the molten weld to the centre, associated with a deeper penetration.
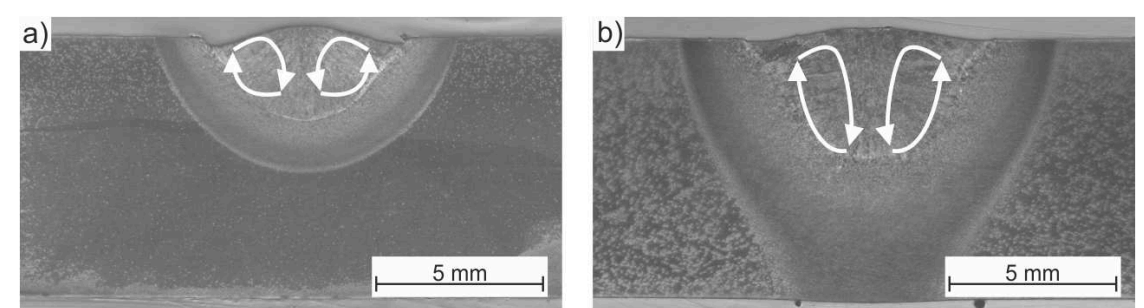

Fig. 3: Macrosections of the TIG-welded dummy seams of the TMCP-steel S960MC with a mill scale: a) test nr. $\left.1, \Delta t_{8 / 5}=3.0 \mathrm{~s}, \mathrm{~b}\right)$ test $\mathrm{nr} .2, \Delta t_{8 / 5}=7.9 \mathrm{~s}$; fluid flow indicated by arrows 
Phase transformation temperatures during cooling after welding. To observe the transformation temperatures for the martensite and bainite transformation at both steels, a Single Sensor Differential Thermal Analysis [13] was realized. In Table 4 the transformation temperatures for all dummy seams are listed, based on the cooling curves registered by the type-K thermo couples and the two colour pyrometer. The very short $\Delta t_{8 / 5}$-cooling times for test $\mathrm{nr} .1$ are indicating a martensitic transformation. For test nr. 2 the higher transformation temperature corresponds to bainite.

Table 5: Transformation start temperatures for TIG-welded dummy seams of both steels

\begin{tabular}{|c|c|c|c|}
\hline Test nr. and material & $\Delta t_{8 / 5}[\mathrm{~s}]$ & Start temperature $\left[{ }^{\circ} \mathrm{C}\right]$ & Microstructure \\
\hline Test nr. 1 S960QL & 2.5 & $442 \pm 5$ & martensite \\
\hline Test nr. 2 S960QL & 9.4 & $470 \pm 5$ & martensite + bainite \\
\hline Test nr. 1 S960MC & 3.0 & $441 \pm 5$ & martensite \\
\hline Test nr. 2 S960MC & 7.9 & $482 \pm 5$ & marteniste + bainite \\
\hline
\end{tabular}

Corresponding to the barely existing differences in the transformation temperatures, the same amounts of martensite, respectively bainite in the weld seams are assumed.

Local Residual Stresses in the weld seam area. At first, the analyses are focused on relations between heat input and the transverse residual stresses $\sigma^{r s}{ }_{y}$. Fig. 4a presents the transverse residual stress distributions $\sigma_{y}^{r s}(y)$ for the TIG-welded dummy seams of the QT-steel S960QL for two different heat inputs $E$ by varied welding speed $v$. Both graphs show tensile residual stresses in the heat affected zone (HAZ) due to inhomogeneous shrinking processes and lowered tensile residual stresses in the weld as a consequence of volume expansion during phase transformation [10,14]. For low heat input $E$ of $0.5 \mathrm{~kJ} / \mathrm{mm}$ a symmetrical distribution $\sigma^{r s} y(y)$ is shown with maximum tensile residual stresses $\sigma^{r s}$ of about $250 \mathrm{MPa}$ at $y= \pm 4 \mathrm{~mm}$ and compressive stresses $\sigma^{r s}$ of $-20 \mathrm{MPa}$ at the weld centre $(y=0 \mathrm{~mm})$. The tensile stresses rise to a maximum of about $400 \mathrm{MPa}$ at $y=4 \mathrm{~mm}$ for the higher heat input $E$ of $0.9 \mathrm{~kJ} / \mathrm{mm}$. In the weld tensile stresses up to $100 \mathrm{MPa}$ can be localized. Thus, a higher heat input increases the transverse residual stresses $\sigma^{r s}$ in the HAZ. Furthermore, the shape of the stress distribution is getting wider.
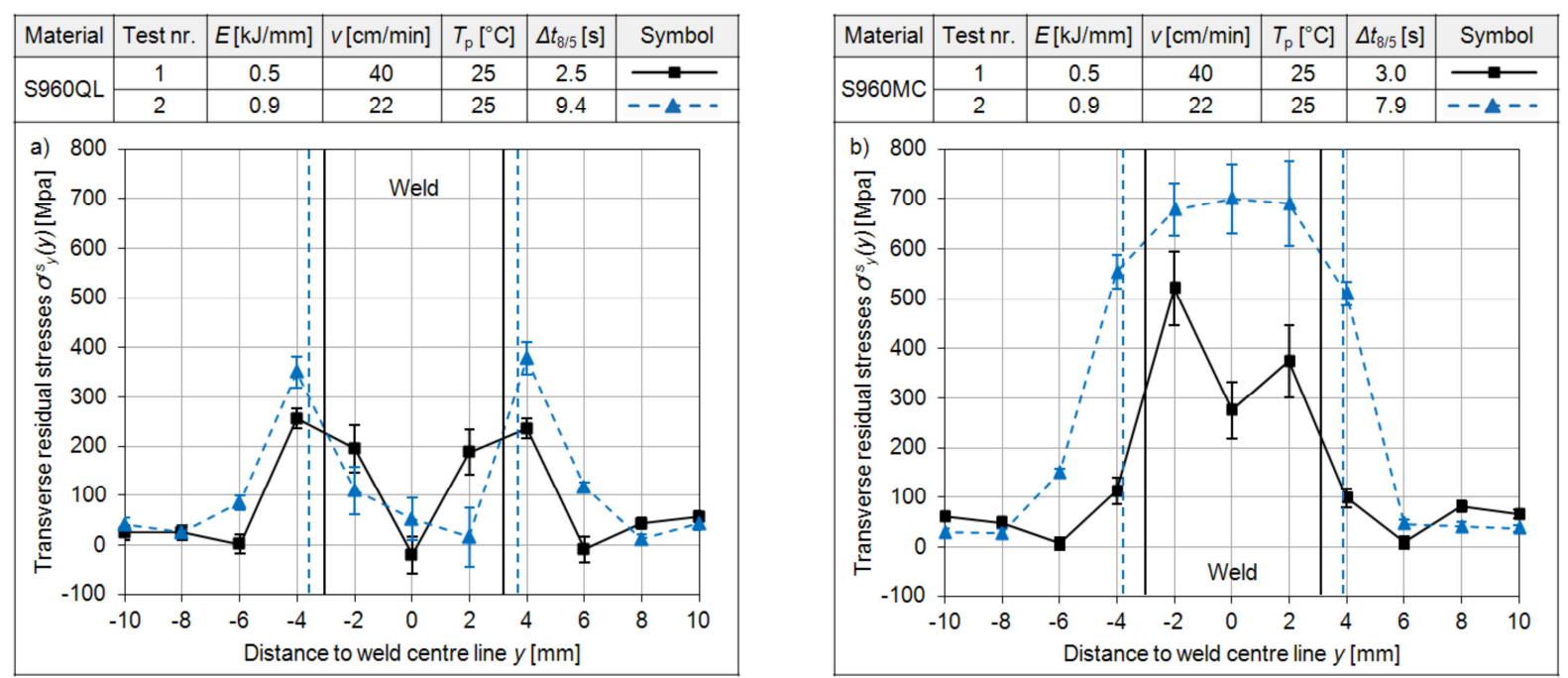

Fig. 4: Transverse residual stress distributions $\sigma^{r s} y(y)$ on the weld seam at seam centre for two different values of heat input $E$ : a) QT-steel S960QL, b) TMCP-steel S960MC with a mill scale

Fig. $4 \mathrm{~b}$ shows the transverse residual stress distributions $\sigma^{r s}(y)$ at the weld seam centre for the TIG-welded dummy seams of the TMCP-steel S960MC for two different heat inputs $E$ by varied welding speed $v$. The small heat input $E$ of $0.5 \mathrm{~kJ} / \mathrm{mm}$ results in a typical distribution $\sigma^{r s} y(y)$ with the phase transformation effect. Maximum tensile residual stresses $\sigma^{r s}$ of about $500 \mathrm{MPa}$ at $y= \pm 2 \mathrm{~mm}$ 
in the weld with a dip in the weld centre $(y=0 \mathrm{~mm})$ is presented. The higher heat input $E$ of $0.9 \mathrm{~kJ} / \mathrm{mm}$ leads to increased tensile stresses over the entire weld seam with a maximum of about $700 \mathrm{MPa}$ in the weld centre $(y=0 \mathrm{~mm})$ and a wider stress distribution. It is remarkable that even for shorter $\Delta t_{8 / 5}$-cooling times of the TMCP-steel, higher residual stresses are generated. The reason is discussed below.

Comparison of the residual stress distributions. In Fig. 5 the transverse residual stress distributions $\sigma^{r s}(y)$ for both steel types are compared for each heat input $E$. In both pictures the TMCPsteel shows higher maximum tensile stresses. Moreover, for the QT-steel the maximum tensile stresses exist in the HAZ. Whereas, for the TMCP-steel those tensile stresses are located in the weld seam.
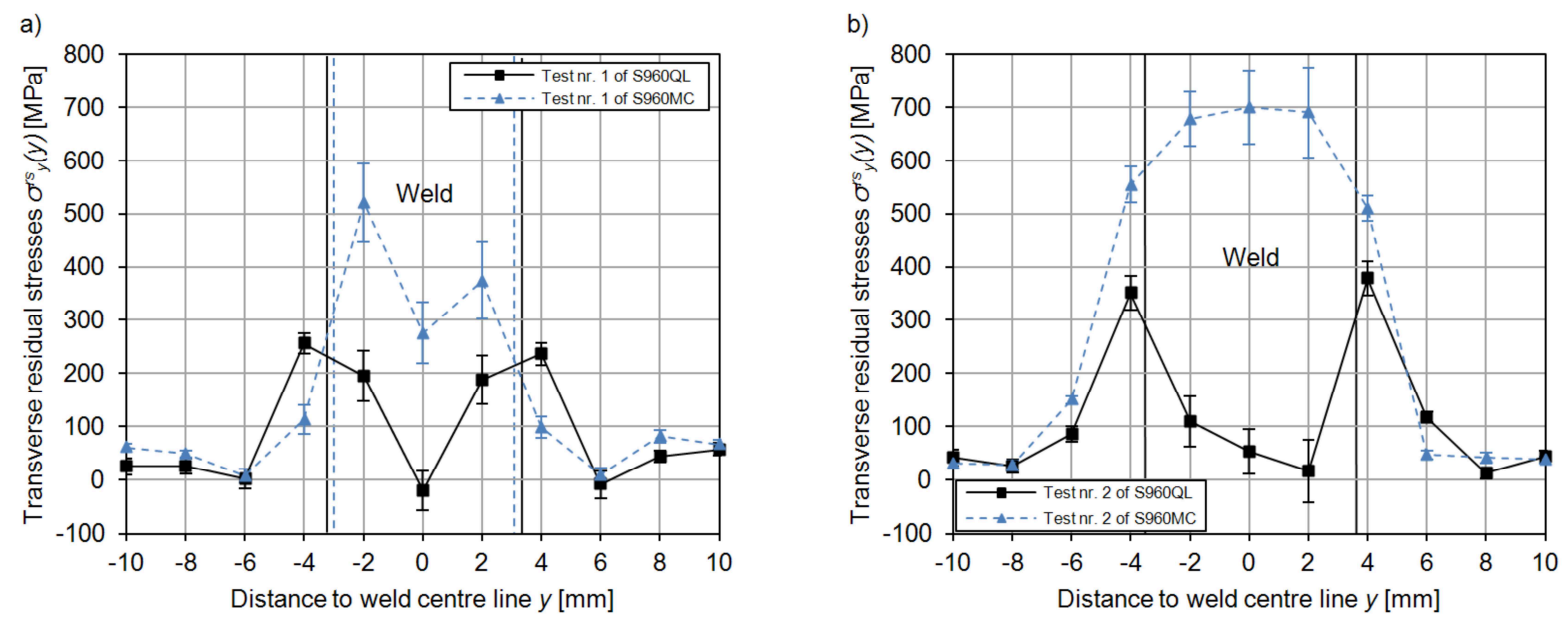

Fig. 5: Comparison of transverse residual stresses $\sigma^{r s} y(y)$ on the weld seam for both steels (seam centre): a) $E=0.5 \mathrm{~kJ} / \mathrm{mm}$, b) $E=0.9 \mathrm{~kJ} / \mathrm{mm}$

For the QT-steel the tensile stresses in the HAZ increase with increasing heat input $E$ because of a larger volume of heated material and the involved inhomogeneous shrinking process. The maintaining of the phase transformation effect in each case for the QT-steel in the weld can be associated with a homogenous transformation into martensite and small amounts of bainite $[10,14]$.

The increased tensile stresses for the TMCP-steel over the entire weld are based on a different effect. For both steels the phase transformations take place at similar temperatures, cp. Table 5 . Therefore, the reason for the significant difference in the distributions cannot be explained with different transformation temperatures. The deeper penetration of the molten bath for the TMCPsteel, cp. Fig. 2 and Fig. 3, leads to an effect, which is described as inhomogeneous transformation [10]. A delayed phase transformation of the core of the weld results in high tensile stresses in the surface of the weld seam.

\section{Conclusions}

In the present study, the influence of heat input on local welding residual stresses in quenched and tempered and thermo-mechanically hot rolled high strength steels was analysed. The following conclusions can be drawn:

1) The local residual stresses in the weld and the HAZ are influenced by the heat input. Higher heat input leads to an increase of the tensile residual stresses in the weld for the TMCP-steel and in the HAZ for the QT-steel as a consequence of a larger heat affected area and phase transformation effects.

2) The results show that significant differences in the transverse residual stress distributions are present when comparing a QT-steel and a TMCP-steel showing a mill scale. The TMCP-steel shows considerably higher tensile residual stresses. 
3) The fluid flow influenced by the elements present in the mill scale leads to a deeper penetration of the material. Consequently, the temperature distribution across the weld is altered leading to a larger heat affected area.

4) The higher temperature gradient across the weld associated with the larger penetration depth in case of the mill scale led to inhomogeneous shrinkage and phase transformation, which can explain the increased tensile residual stresses in the surface of the weld and the HAZ.

5) From viewpoint of welding a mill scale may considerably influence the fluid flow in the weld and therefore the temperature distribution, which in consequence may alter the residual stress distribution in the weld as well as the heat affected zone.

\section{References}

[1] K. Hulka, A. Kern, U. Schriever, Application of Niobium in Quenched and Tempered HighStrength Steels, Mater. Sci. Forum 500-501 (2005) 519-526.

[2] Y. Nie, C. Shang, Y. You, X. Li, J. Cao, X. He, 960 MPa Grade High Performance Weldable Structural Steel Plate Processed by Using TMCP, J. Iron Steel Res. Int. 17 (2010) 63-66.

[3] M. Klein, H. Spindler, A. Luger, R. Rauch, P. Stiaszny, M. Eigelsberger, Thermomechanically Hot Rolled High and Ultra High Strength Steel Grades - Processing, Properties and Application, Mater. Sci. Forum 500-501 (2005) 543-550.

[4] R.Y. Chen, W.Y.D. Yuen, Oxide-Scale Structures Formed on Commercial Hot-Rolled Steel Strip and Their Formation Mechanisms, Oxidat. Metal. 56 (2001) 89-118.

[5] P. Sahoo, T. Debroy, M.J. McNallan, Surface Tension of Binary Metal - Surface Active Solute Systems under Conditions Relevant to Welding Metallurgy, Metall. Mater. Trans. B 19 (1988) 483-491.

[6] Y. Zhao, H. Zhou, Y. Shi, The study of surface active element on weld pool development in A-TIG welding, Model. Simul. Mater. Sci. Eng. 14 (2006) 331-349.

[7] S. Lu, H. Fuji, K. Nogi, Marangoni Convection and Gas Tungsten Arc Weld Shape Variations on Pure Iron Plates, ISIJ Int. 46 (2006) 276-280.

[8] C.R. Heiple, J.R. Roper, R.T. Stagner, R.J. Aden, Surface Active Element Effects on the Shape of GTA, Laser, and Electron Beam Welds, Weld. J. 62 (1983) 72s-77s.

[9] C.R. Heiple and J.R. Roper, Mechanism for Minor Element Effect on GTA Fusion Zone Geometry, Weld. J. 61 (1982) 97s-102s.

[10] T. Nitschke-Pagel and H. Wohlfahrt, Residual Stresses in Welded Joints - Sources and Consequences, Mater. Sci. Forum 404-407 (2002) 215-226.

[11] EN 1011-1, Welding - Recommendation for welding of metallic materials - Part 1: General guidance for arc welding, 2007.

[12] EN 1090-2, Execution of steel structures and aluminium structures - Part 2: Technical requirements for steel structures, 2008.

[13] B.T. Alexandrov and J.C. Lippold, Single Sensor Differential Thermal Analysis of Phase Transformations and Structural Changes During Welding and Postweld Heat Treatment, Weld. World 51 (2007) 48-59.

[14] T. Nitschke-Pagel and H. Wohlfahrt, The Generation of Residual Stresses due to Joining Processes, in: V. Hauk, H. Hougardy, E. Macherauch (Eds.), Residual Stresses Measurement, Calculation, Evaluation, DGM Informationsgesellschaft mbH, 1991, pp. 121133. 